sequence, which is now 15 per cent complete, and is expected to be finished by the end of 1998 , costs about 50 cents a base.)

Some remain sceptical about whether the figure can indeed be reduced this low. "We have yet to see anything on paper to allow us to judge whether it is feasible," says one sequencer while admitting that, in principle, he is strongly supportive of the approach that Sulston and Waterston are taking.

Even at this low price, however, Sulston is keen to emphasize that, for scientific and other reasons, he would like to see the project carried out collaboratively between a number of centres, with different research groups agreeing to concentrate on different chromosomes.

Such an approach is likely to go some way to meeting fears that arose earlier this year, when the proposals were first being discussed by genome research centres, that the whole project would be dominated by the Sanger Centre and the St Louis group. "We have each said that we would be willing to do one third of the operation, but we do not insist on doing it all; the intention is to have a fully cooperating network."

Cooperation - not competition (apart from that for funding, with peer review ensuring the quality of the data produced) - will be the key. "This is a place where the market does not work well," says Sulston. "It is inappropriate when you are trying to establish a framework where there is only one solution; you need a strategic plan."

David Bentley, head of human genetics at the Sanger Centre, suggests as a possible model the consortium of laboratories set up in Europe, with the backing of the European Commission in Brussels, to sequence the yeast genome. "It has been put together in a very informal and flexible way, and people have shifted their aspirations according to what they have been able to achieve," says Bentley. "We will try to work in the same way with the human genome."

If the consensus behind the overall strategy is still growing, it is not yet complete. Some still argue, for example, that a more effective approach would be to build on the knowledge of detailed sequences being established through cDNA libraries, in other words starting with a focus on functioning genes. Others continue to prefer a strategy known as 'skimming' the genome, carrying out the complete sequencing of randomly selected sections.

The Cold Spring Harbor meeting is expected to provide a forum for vigorous debate between those supporting rival strategies. But for Sulston, Waterston and their colleagues, the funding agencies prepared to back their approach, and industrial researchers keen to exploit their results, the main question now is not whether, but when, to start work. If the proposed pilot projects succeed, the main sequencing would be ready to start by the end of the next year. And the whole project could be finished by the year 2001 - five years earlier than many had previously estimated.

\title{
US court rules discovery of gene sequence 'not obvious'
}

London. In a major boost to the biotechnology industry, a US appeals court has ruled that the discovery of a novel gene sequence cannot be described as 'obvious' - and that the sequence in question can therefore be legitimately included in a patent - even if the existence of the gene was previously known, as were techniques for obtaining its complementary DNA (cDNA).

The ruling is based on the fact that, even though the gene can be deduced from the protein that it expresses, so-called 'redundancy' in the genetic code means that its precise nucleotide sequence can be considered unknown until it has been 'discovered'. (The redundancy results from the fact that more than one nucleotide base triplet in a DNA sequence can code for the same amino acid in the protein, and that a wide range of sequences can therefore theoretically code for the same protein.)

The court's decision is a direct challenge to those who have been arguing that the controversy over patents on human and animal genes is likely to blow over relatively quickly as sequencing and cloning techniques become routine laboratory practice, and the discovery of new gene sequences, therefore, a relatively unremarkable affair.

Indeed, one of the main implications of the ruling is to limit the range of techniques whose existence can be invoked to dismiss a discovery as 'obvious', and therefore to increase the degree of predictability in the US patents system.

At the same time, the ruling is being seen in the biotechnology industry as putting gene sequences on the same level - at least as far as patent protection is concerned - as chemical molecules, whose eligibility for patent protection (provided they fulfil criteria of novelty and usefulness) is clear.

"The implication is that new technologies in the biotechnology and genomics area can be covered by existing patent laws in the same way as other areas such as chemistry and physics," says Robert Benson, attorney for Human Genome Sciences (HGS) Inc. in Rockville, Maryland. HGS has over 70 patent applications on partial and full gene sequences awaiting a ruling from the US Patents and Trademark Office (PTO), and hopes the court ruling will increase their chances of being approved.

The decisions concern the application by Thomas F. Deuel and three fellow scientists at Washington University in St Louis, Missouri, for a patent on isolated and purified DNA and cDNA molecules encoding heparin-binding growth factors (HBGFs), proteins that stimulate cell division and therefore facilitate the repair or replacement of damaged or diseased tissue.
A PTO examiner had initially rejected the patent application - which includes coverage on all possible DNA molecules coding for the disclosed proteins - on the grounds that cloning the gene would have been "obvious" to anyone "of ordinary skill in the art at the time of the invention".

The examiner quoted two instances of 'prior art' to support this view. One was that a heparin-binding protein had already been identified and isolated from human and bovine brain tissue, and both proteins had been found to share the first 19 amino acids in their $\mathrm{N}$-terminal sequences. The second was that methods for isolating either DNAs or cDNAs by screening sequence libraries had been initially described by Tom Maniatis of Harvard University in 1982.

The examiner argued that it would have been relatively straightforward to use the known $\mathrm{N}$-terminal sequence, and the techniques described by Maniatis, to design a probe to isolate a gene encoding the protein from a cDNA library. Although challenged by the applicants, the ruling was subsequently upheld in November 1993 by the PTO's own appeals board.

Last month, however, in response to a challenge mounted with the backing of both the Biotechnology Industry Association and the Bay Area Science Centre in San Francisco, as well as biotechnology companies such as Chiron Inc., the US Federal Circuit court overturned the PTO's objection.

The court ruled that, even though knowledge about the proteins identified earlier meant the general chemical nature of the cDNA molecules in the patent claims "may have been obvious" - and the knowledge that "some gene existed" may have been clear - redundancy in the genetic code meant that the precise cDNA molecules isolated from the library "would not have been obvious".

"Until the claimed molecules were actually isolated and purified, it would have been highly unlikely to one of ordinary skill in the art to contemplate what was ultimately obtained," said the court. "What cannot be contemplated or conceived cannot be obvious."

More broadly, the court stated that a general motivation to search for some gene that exists "does not necessarily make obvious a specifically-defined gene that is subsequently obtained as a result of that search".

It added: "Even if, [. . .] the existence of general cloning techniques, coupled with knowledge of a protein's structure. might have provided motivation to prepare $a$ cDNA or made it obvious to prepare $a$ cDNA, that does not necessarily make obvious a particular claimed cDNA". D. D. 